\title{
Anatomia Quantitativa da Folha e do Colmo de Brachiaria brizantha (Hochst. ex A. Rich.) Stapf e B. humidicola (Rendle) Schweick.
}

\author{
Cláudio José Freixeiro Alves de Brito ${ }^{1}$, Roberto Antonio Rodella ${ }^{2}$, Francisco Carlos Deschamps ${ }^{3}$
}

\begin{abstract}
RESUMO - As características da digestão das forragens podem ser mais bem compreendidas quando complementadas com estudos de anatomia dos tecidos de plantas forrageiras. Com o objetivo de agregar novas informações ao tema, determinou-se a área dos diversos tecidos presentes na folha e no colmo de Brachiaria brizantha e B. humidicola, em três diferentes níveis de inserção no perfilho. O experimento foi conduzido em casa de vegetação, com plantas mantidas em vasos plásticos contendo areia esterilizada e recebendo solução nutritiva de macro e micronutrientes. Após 70 dias do corte de uniformização das parcelas (vasos), coletou-se o segmento do colmo e da folha (limbo e bainha) situado na porção mediana de cada um dos três diferentes níveis de inserção do perfilho estudado. As amostras foram emblocadas em GMA, seccionadas em micrótomo e o laminário fotomicrografado. As fotografias foram digitalizadas e as áreas de tecidos, mensuradas com software Image Tool. Observou-se que o limbo das folhas basilares apresentou menor área de tecido vascular lignificado. Maior área de tecido parenquimático foi observada na bainha e no colmo da B. brizantha. Em relação à $B$. humidicola, a $B$. brizantha apresentou maior área de tecido vascular lignificado no limbo, bainha e colmo. Maior distância entre os feixes vasculares foi observada no limbo e na bainha, sendo o número de feixes maior no limbo e no colmo.
\end{abstract}

Palavras-chave: anatomia vegetal, celulose, forragens, gramíneas, lignina

\section{Quantitative Anatomy of Leaves and Stems of Brachiaria brizantha (Hochst. ex A. Rich.) Stapf and B. humidicola (Rendle) Schweick.}

\begin{abstract}
The forage digestion characteristics can better be understood when associated with studies of tissue anatomy of forage species. Aiming at new focus to this issue, the area of several tissues present in leaves and stems of B. brizantha and B. humidicola, were determined at three different regions of the plant. The assay was carried out at greenhouse, with plants growing in pots with sterilized sand, receiving nutritive solution of macro and micronutrients. After 70 days of growing period, the segment of leaf and stem localized in the center of each of three different insertion planes was collected. The samples were fixed in FAA, embedded in GMA, sectioned in microtome, stained and photographed. The pictures were digitalized and the areas measured with Image Tool software. It was observed that the limbo at bottom plane presents lower area of lignified vascular tissue. On the other hand, at the sheath and stem of $B$. brizantha, a larger area of parenchymal tissue is found. Compared to B. humidicola, B. brizantha showed greater area of lignified vascular tissue at the limbo, sheath and stem, while the greatest distance among bundle sheath is found at the limbo and sheath, where the number of bundle sheath was higher at the limbo and stem.
\end{abstract}

Key words: cellulose, forage, grasses, lignin, plant anatomy

\section{Introdução}

Brachiaria brizantha (Hochst. ex A. Rich.) Stapf e Brachiaria humidicola (Rendle) Schweick. são forrageiras perenes tropicais muito utilizadas na formação de pastagens para bovinos em todo o Brasil.

Atualmente, a anatomia vegetal quantitativa tem se constituído em uma ferramenta complementar interessante para os estudos de avaliação da qualidade das forrageiras. Indicadores gerados pela técnica permitem tanto a comparação de espécies ou cultivares, como o acompanhamento do envelhecimento dos tecidos com a maturidade da planta. No Brasil, alguns estudos comprovaram a ocorrência da associação entre anatomia e qualidade das forrageiras (Rodella et al., 1982; Ventrella, 1995; Ventrella et al., 1997a; 1997b; Alves de Brito, 1997; Lima, 1998; Alves de Brito et al., 1997a, 1997b, 1999). Utilizando microscopia eletrônica de varredura, foi possível observar que a biota ruminal digere vários tipos de

\footnotetext{
${ }^{1}$ Engenheiro-Agrônomo, Doutor em Botânica, Professor Titular, UNIANDRADE. Cx. Postal623, 80.011-970, Curitiba, PR, Brasil (cjbrito@ hotmail.com) 2 Engenheiro-Agrônomo, Doutor em Botânica, Professor Assistente-Doutor, UNESP. Cx. Postal 510, 18.618-000, Botucatu, SP, Brasil. (rodella@ibb.unesp.br)

${ }^{3}$ Médico Veterinário, Doutor em Bioquímica, Pesquisador, EPAGRI S.A./UNIVALI. Cx. Postal 277, 88.301-970, Itajaí, SC, Brasil. (xicodsc@ hotmail.com)
} 
tecido das forrageiras, sendo o tecido vascular lignificado o mais resistente a digestão (Alves de Brito et al., 1999). No mesmo estudo, os autores descrevem que a degradação dos tecidos obedece a seguinte ordem decrescente: tecido parenquimático $>$ floema $>$ epiderme $>$ bainha parenquimática $>$ xilema e esclerênquima. Esta sequência já havia sido constatada também em outros estudos.

Em ruminantes, a taxa de degradação da parede celular das forragens é determinada, em grande parte, pela capacidade da biota ruminal em transpor barreiras anatômicas. Desse modo, a quantificação dos tecidos presentes nas forrageiras pode auxiliar a compreender melhor a qualidade nutricional da forragem (Alves de Brito et al., 1997a; 1999; Deschamps \& Alves de Brito, 1998; Ventrella et al., 1997a, b).

A capacidade de consumo dos ruminantes está associada à forrageira fornecida aos animais. Nesse caso, o consumo pode diminuir com o incremento da maturidade da planta, pela redução da qualidade nutricional de seus tecidos.

O presente trabalho foi conduzido com o objetivo de determinar a proporção dos tecidos encontrados no limbo foliar, na bainha e no colmo, localizadas em diferentes níveis de inserção de plantas de Brachiaria brizantha e $B$. humidicola.

\section{Material e Métodos}

O material vegetal utilizado foi representado por folhas (lâminas e bainhas foliares) e colmos de B. brizantha (Hochst. ex A. Rich.) Stapf e de B. humidicola (Rendle) Schweick.

O experimento foi conduzido na Empresa Catarinense de Pesquisa e Extensão Agropecuária EPAGRI S.A., Estação Experimental de Itajaí, Santa Catarina, Brasil (265'ㄹ'” S, 48³9'43”'W, 5 m.s.m.).

As mudas foram plantadas em vasos plásticos mantidos em casa de vegetação, contendo areia esterilizada como suporte, e receberam por gotejamento automático solução nutritiva constituída de macro e microelementos minerais necessários para seu adequado desenvolvimento.

Aos 70 dias após o corte de uniformização das parcelas (vasos em número de cinco), coletaram-se indivíduos (perfilhos) pertencentes às duas espécies. Cada planta foi dividida em três regiões (apical, central e basilar), considerando-se como comprimento total da planta o primeiro (basilar) e o último (apical) nó visível no colmo. De cada terço selecionado (estrato) foi coletada a folha que ocupava a região central, retirando-se a porção média da lâmina (limbo) e da bainha foliar, bem como a porção média do entrenó (colmo) recoberto pela bainha foliar amostrada.

O estudo anatômico foi realizado junto ao Laboratório de Anatomia Vegetal, do Departamento de Botânica, do Instituto de Biociências de Botucatu - UNESP.

As amostras foram fixadas em FAA 50\%, por aproximadamente 48 horas, e depois conservadas em etanol $70 \%$, para posterior desidratação com a incrementação da concentração de etanol até $100 \%$ (Johansen, 1940). Após este processo, as amostras foram emblocadas em glicol metacrilato (GMA) JB-4 (Polysciences, Inc.), seguindo-se as recomendações do fabricante e de Feder \& O'Brien (1968). Os blocos foram então seccionados transversalmente em micrótomo rotatório Leica RM-2145, com os cortes distendidos em água e corados com solução aquosa de Fucsina Básica 0,0125\% e Azul de Astra 1,0\% (Alves de Brito \& Alquini, 1996). Uma vez efetuada a dupla coloração, as lâminas foram lavadas em água corrente, secas em estufa a $40^{\circ} \mathrm{C}$ e submetidas à montagem convencional e recobertas com lamínula. Após a confecção do laminário, as secções foram fotomicrografadas em equipamento Zeiss-Axiolab.

As fotografias foram digitalizadas em scanner e os tecidos, mensurados com software Image Tool, consoante Alves de Brito \& Deschamps (1998). A delimitação dos tecidos para a determinação da área (\%) ocupada levou em consideração a descrição usual em histologia vegetal, considerando a área dos seguintes tecidos: a) tecido epidérmico (excluindo-se tricomas e células buliformes); b) área de células buliformes; c) de tecido parenquimático; d) tecido vascular não lignificado (basicamente floema); e) tecido vascular lignificado + esclerênquima (xilema, fibras e outras células lignificadas do feixe vascular); f) porcentagem de bainha parenquimática (Figuras 1 e 2). Também foram determinadas a quantidade e a distância entre os feixes vasculares.

Para padronização das áreas mensuradas, no limbo utilizou-se um segmento abrangendo um feixe de grande porte e dois de médio porte (Figuras 1-A e 2-A) e na bainha foliar, dois feixes de grande porte (Figuras 1-B e 2-B). No colmo, foi scaneada uma área de $8 \times 8 \mathrm{~cm}$, pré-determinada pelo próprio digitalizador e sobreposta na foto, sendo mensurados todos os tecidos incluídos neste quadrado (Figuras 1-C e 2-C).

Foi utilizado o delineamento experimental inteira- 


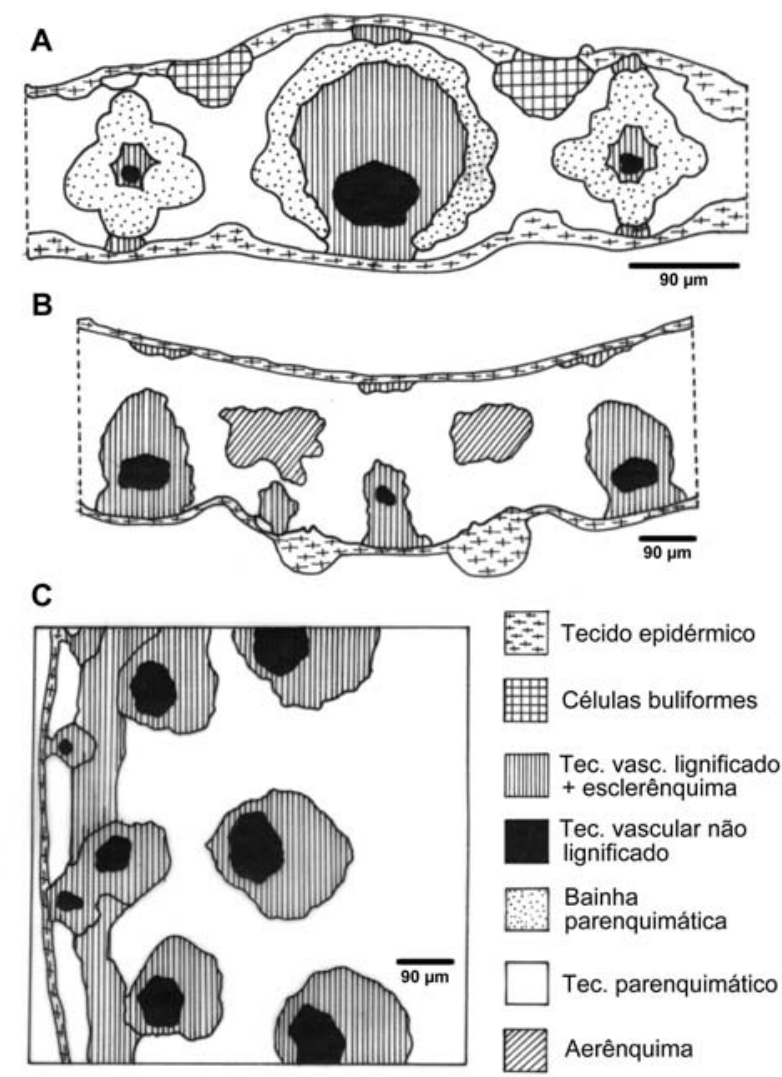

Figura 1 - Desenhos esquemáticos de Brachiaria brizantha, representando os segmentos mensurados. A - Região do limbo; B - Bainha foliar; C - Colmo.

Figure 1 - Schematical draws of Brachiaria brizantha, representing the measured tissues. $\boldsymbol{A}$ - Blade region; $\boldsymbol{B}$ - Leaf sheath; $\boldsymbol{C}$ - Stem.

mente casualizado, com cinco repetições, em parcelas subdivididas, considerando-se como tratamento principal as duas espécies e, como tratamento secundário, as regiões. Os dados de porcentagens foram transformados em arcsen $\sqrt{\mathrm{x}}$ e os de contagens, em $\sqrt{\mathrm{x}}$. As médias foram comparadas por intermédio do teste Tukey, a 5\% de probabilidade (Pimentel Gomes, 1976).

\section{Resultados e Discussão}

Os resultados referentes à anatomia quantitativa de $B$. brizantha e $B$. humidicola, das frações limbo, bainha foliar e colmo, estão apresentados nas Tabelas 1,2 e 3.

Comparando-se as duas espécies, constatou-se

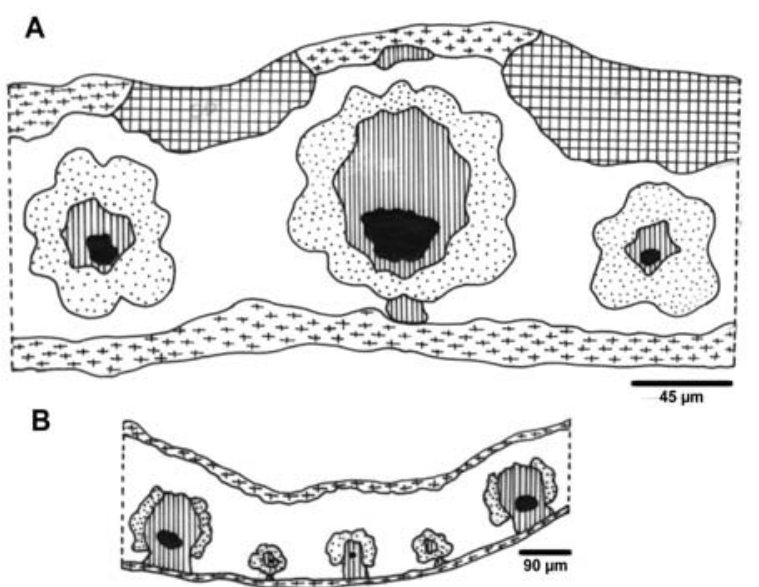

C
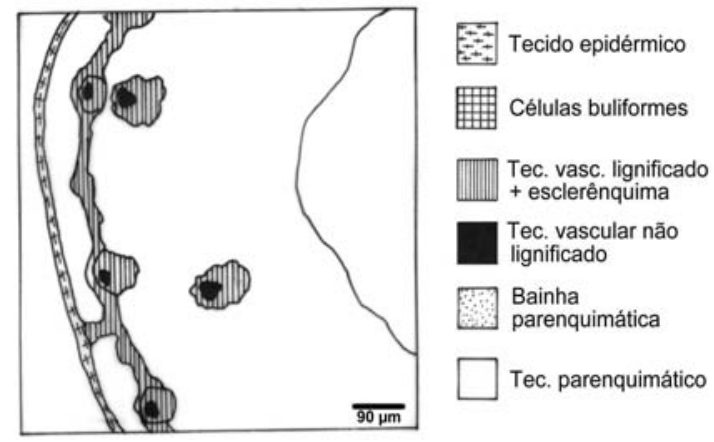

Figura 2 - Desenhos esquemáticos de Brachiaria humidicola, representando os segmentos mensurados. A - Região do limbo; B - Bainha foliar; C - Colmo, apresentando medula oca (P).

Figure 2 - Schematical draws of Brachiaria humidicola, representing the measured tissues. A - Blade region; $\boldsymbol{B}$ - Leaf sheath; $\boldsymbol{C}$ - Stem with hollow centre.

que $B$. humidicola apresentou maior porcentagem de tecido epidérmico nas frações do limbo central (Tabela 1) e colmo basilar e apical (Tabela 3). Para a fração bainha foliar (Tabela 2) houve diferença significativa apenas na média geral entre as espécies, destacando-se $B$. humidicola com maior valor de tecido epidérmico. Entre os níveis de inserção, para as duas espécies estudadas, não foi observado aumento da porcentagem de epiderme no sentido basilar-apical do limbo e da bainha, como descrito por Wilson (1976), em Panicum maximum.

A área ocupada pelas células buliformes encontradas no limbo (Tabela 1) foi mais elevada em B. humidicola, sem haver diferenciação significativa entre os níveis de inserção das plantas. Este tipo de 
célula epidérmica é considerada de alta degradação, pois se assemelha às parenquimáticas, apresentando paredes celulares delgadas e recobertas por uma fina cutícula, com composição química distinta daquela que recobre as demais células epidérmicas (Wilson, 1976; Alves de Brito, 1997).

Com relação à área ocupada pela bainha parenquimática no limbo, não houve diferença entre os níveis de inserção para as espécies estudadas na fração limbo (Tabela 1), ocorrendo maior valor apenas na média geral das regiões de $B$. brizantha. Na bainha foliar (Tabela 2), somente $B$. humidicola apresentou a bainha parenquimática ao redor dos feixes vasculares (Figura 2-B).

Os tecidos lignificados, considerados restritivos com relação a digestão, apresentaram-se em maior proporção na $B$. brizantha, em todas as frações (Tabelas 1, 2 e 3). Comparando-se as regiões das plantas, verifica-se que no limbo (Tabela 1) há maior proporção destes tecidos nas folhas da região superior. Resultados semelhantes foram relatados por Wilson (1976) e Rodella et al. (1982), trabalhando com mensurações dos tecidos da região da quilha de B. mutica e B. brizantha, em três níveis de inserção. Nas frações bainha foliar (Tabela 2) e colmo (Tabela 3), não houve diferença significativa entre os níveis de inserção. O fato de a maior proporção de tecidos lignificados comprometer a digestibilidade de forrageiras é amplamente descrito na literatura. Contudo, alguns trabalhos mais recentes (Jung \& Buxton, 1994; Jung \& Allen, 1995; Jung \& Ni, 1998; Deschamps, 1999; Hatfield et al., 1999a; 1999b) creditam à composição química da parede celular, principalmente dos compostos da lignina, diferentes graus de digestibilidade em materiais com proporções de tecidos lignificados e/ou teores de lignina semelhantes. A forma como os ácidos ferúlico e p_cumárico estão associados à lignina afeta a digestibilidade da matéria seca (Hatfield et al., 1999a). Assim, frações que apresentem a mesma área de tecidos lignificados podem apresentar resistência diferenciada à digestão.

O tecido vascular não lignificado, apesar de altamente digerível, apresentou proporções insignificantes em todas as frações (Tabelas 1, 2 e 3), não afetando o potencial digestivo das espécies.

O tecido parenquimático, muito desejável em termos de degradação, além de ocupar grande parte da área total de todas as frações da planta, revelouse mais abundante na bainha foliar (Tabela 2) e no colmo (Tabela 3) de B. brizantha, porém sem diferir entre os níveis de inserção. Com relação ao limbo (Tabela 1), B. humidicola apresentou maior proporção desse tecido no estrato apical, enquanto $B$. brizantha apresentou maior valor no estrato central. Para o estrato basilar não houve diferença significativa entre as espécies. $\mathrm{Na}$ grande maioria dos trabalhos realizados com anatomia quantitativa, associada à degradação ruminal, o tecido parenquimático encontra-se somado à área de células buliformes, por afinidades estruturais. Dessa forma, somando-se tecido parenquimático e células buliformes, constata-se que $B$. humidicola possui maior porcentagem desses tecidos altamente digeríveis.

A quantificação anatômica de $B$. brizantha, a partir de limbos da região apical, realizada por Paciullo et al. (1999), mostrou valores bastante semelhantes aos encontrados no presente trabalho, como $23,6 \%$ de epiderme (incluindo as células buliformes), $35,9 \%$ de parênquima, $28,8 \%$ de bainha parenquimática e $11,7 \%$ do conjunto xilema, floema e esclerênquima.

Sabe-se que os feixes vasculares em disposição paralela, característica das folhas de gramíneas, conferem grande resistência física ao limbo. Assim, espera-se que, quanto maior o número de feixes e menor a distância entre eles, mais difícil seja a ruptura dessas frações, quando da apreensão pelos animais, especialmente por bovinos. A maior distância entre feixes observados no limbo (Tabela 1) e na bainha (Tabela 2) de B. brizantha pode conferir a estas frações maior facilidade de ruptura. Em B. humidicola, o limbo apical apresentou tendência de feixes mais distantes que nos demais níveis de inserção, porém não diferindo significativamente $(\mathrm{P}>0,05)$. Isto pode ser indicativo da facilidade de apreensão das folhas deste nível de inserção e da dificuldade nos demais. A distância entre os feixes do limbo apical das duas espécies não diferiu ( $\mathrm{P}>0,05)$, enquanto, nos demais níveis de inserção, os feixes de $B$. humidicola apresentaram distâncias menores que os de $B$. brizantha.

Quanto ao número total de feixes vasculares, verifica-se que, no limbo (Tabela 1), B. brizantha apresenta quase o dobro de feixes que B. humidicola, em todos os níveis de inserção estudados. Isto se deve às dimensões do limbo de $B$. brizantha, que possui o dobro da largura apresentada por $B$. humidicola. Na fração bainha (Tabela 2), não houve diferença entre as espécies e no colmo (Tabela 3); B. brizantha apresentou 
Tabela 1- Área (\%) dos tecidos, distância e número de feixes vasculares no limbo de Brachiaria brizantha e $B$. humidicola, em três regiões da planta

Table 1 - Tissue area (\%), number and distance among vascular bundles in limbo of Brachiaria brizantha and $B$. humidicola, at three plant regions

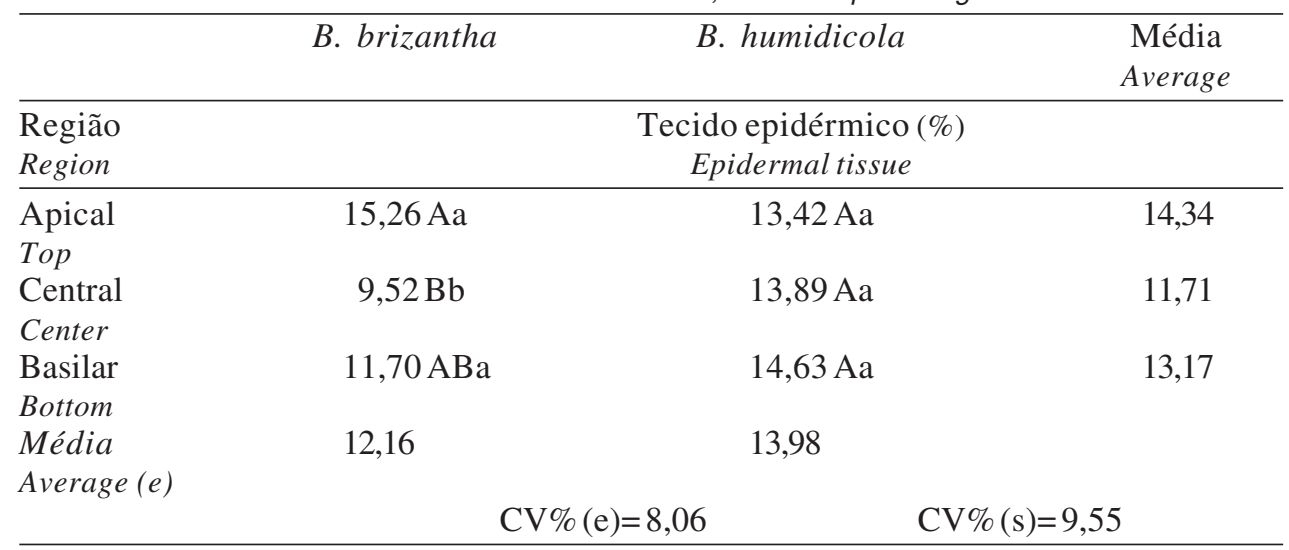

Células buliformes $(\%)$

Buliform cells

\begin{tabular}{lccc}
\hline $\begin{array}{l}\text { Apical } \\
\text { Top }\end{array}$ & 9,32 & 15,00 & $12,16 \mathrm{~A}$ \\
$\begin{array}{l}\text { Central } \\
\text { Center }\end{array}$ & 8,13 & 16,48 & $12,31 \mathrm{~A}$ \\
$\begin{array}{l}\text { Basilar } \\
\text { Bottom }\end{array}$ & 7,33 & 18,12 & $12,73 \mathrm{~A}$ \\
Média & $8,26 \mathrm{~b}$ & $16,53 \mathrm{a}$ & \\
Average $(e)$ & &
\end{tabular}

Average (e)

CV\% (e)=10,49

$\mathrm{CV} \%(\mathrm{~s})=9,55$

Bainha parenquimática $(\%)$

\begin{tabular}{lccc} 
& \multicolumn{3}{c}{} \\
\hline $\begin{array}{l}\text { Apical } \\
\text { Top }\end{array}$ & 24,26 & 20,10 & $22,18 \mathrm{AB}$ \\
$\begin{array}{l}\text { Central } \\
\text { Center }\end{array}$ & 23,20 & 20,52 & $21,86 \mathrm{~B}$ \\
Basilar & 26,52 & 22,16 & $23,34 \mathrm{~A}$ \\
Bottom & $24,66 \mathrm{a}$ & $20,93 \mathrm{~b}$ & \\
Média & &
\end{tabular}

Average (e)

CV\% (e) $=4,09$

$\mathrm{CV} \%(\mathrm{~s})=4,97$

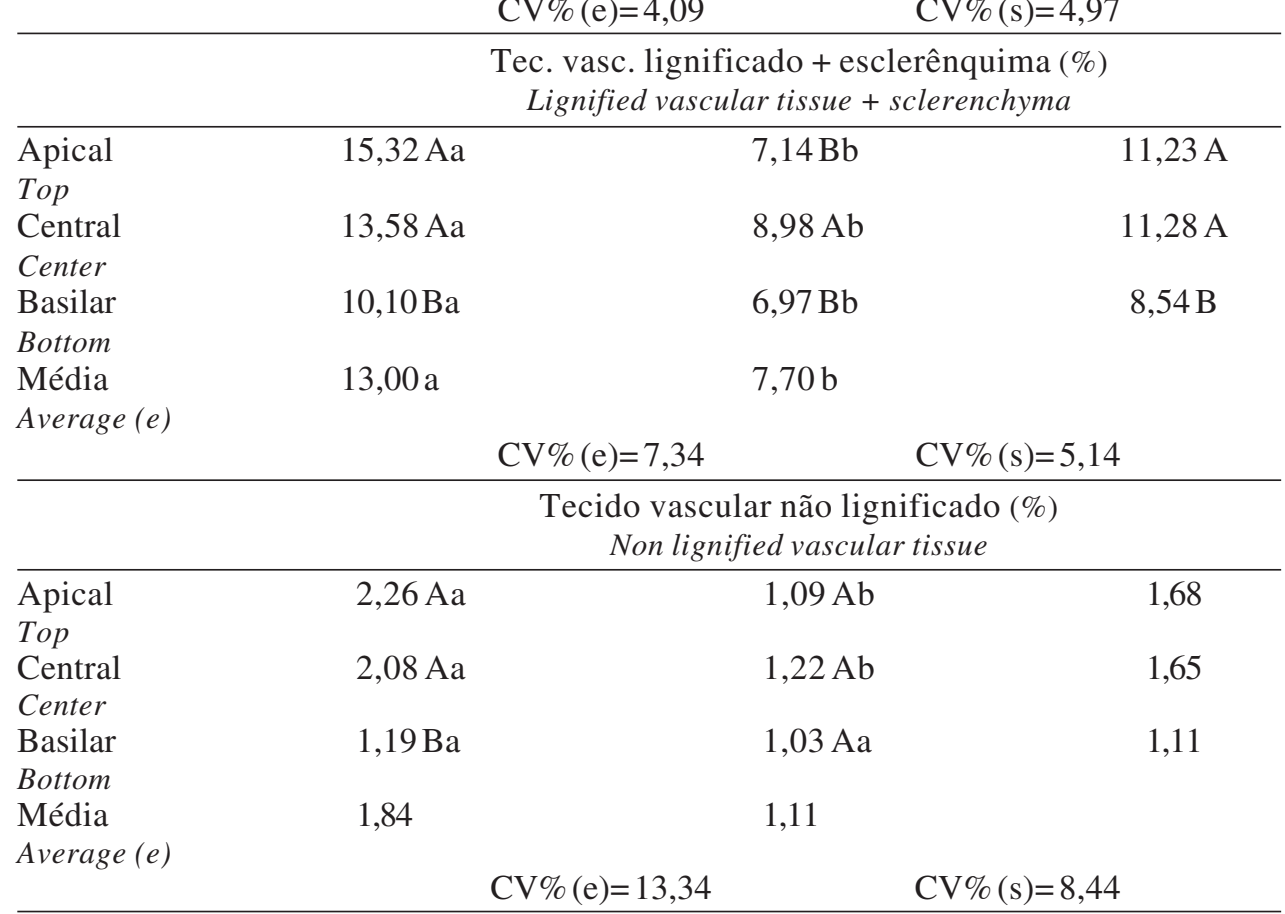

R. Bras. Zootec., v.33, n.3, p.519-528, 2004 
Continuação da Tabela $1 \ldots$

\begin{tabular}{lccc}
\hline & B. brizantha & B. humidicola & Média \\
Average
\end{tabular}

(s) - Região; (e) - espécies.

(s) - Region; (e) - species.

Letras iguais maiúsculas na coluna e minúsculas na linha não diferem significativamente $(P>0,05)$.

Averages followed by the same capital letters in a column and small letters in row do not differ (P>.05).

maior número total de feixes, nas três regiões estudadas. Estes dados estão associados ao diâmetro do colmo e, principalmente, à espessura da parede do colmo. Ambas as espécies apresentam medula oca, sendo que em $B$. brizantha esta medula é bem menor, proporcionando uma parede do colmo mais espessa, mesmo com diâmetros de colmo semelhantes entre as espécies. 
Tabela 2 - Área (\%) dos tecidos, distância e número de feixes vasculares na bainha foliar de Brachiaria brizantha e B. humidicola, em três regiões da planta

Table 2 - Tissue area, number and distance among vascular bundles in leaf sheath of Brachiaria brizantha and $B$. humidicola, at three plant regions

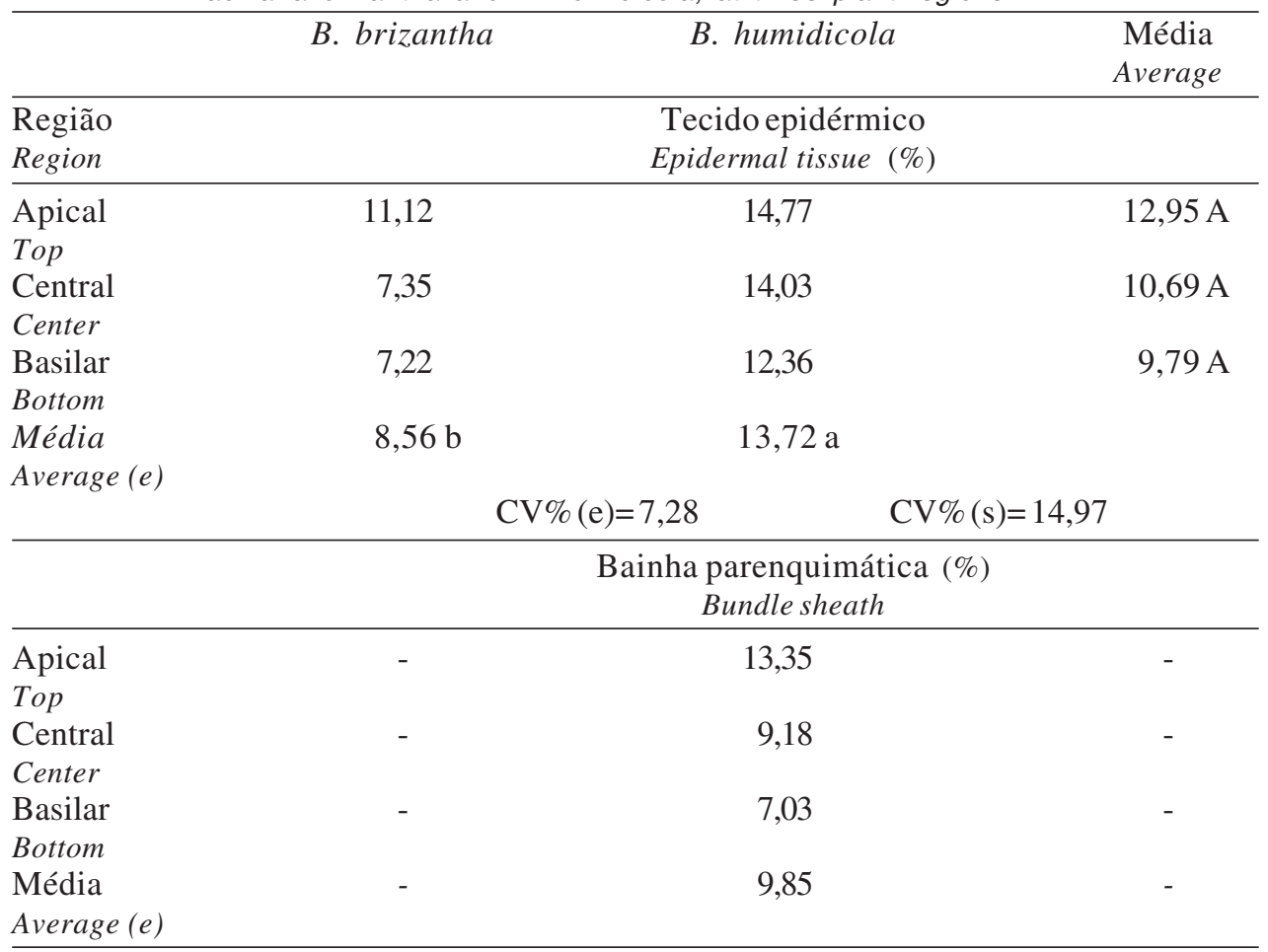

Average (e)

Tec. vasc. lignificado + esclerênquima (\%)

Lignified vascular tissue + sclerenchyma

\begin{tabular}{|c|c|c|c|}
\hline Apical & 21,79 & 13,78 & $17,79 \mathrm{~A}$ \\
\hline Top & & & \\
\hline $\begin{array}{l}\text { Central } \\
\text { Center }\end{array}$ & 20,58 & 14,66 & $17,62 \mathrm{~A}$ \\
\hline $\begin{array}{l}\text { Basilar } \\
\text { Bottom }\end{array}$ & 21,31 & 11,08 & $16,20 \mathrm{~A}$ \\
\hline $\begin{array}{l}\text { Média } \\
\text { Average (e) }\end{array}$ & $21,23 \mathrm{a}$ & $13,17 \mathrm{~b}$ & \\
\hline & & & \\
\hline
\end{tabular}

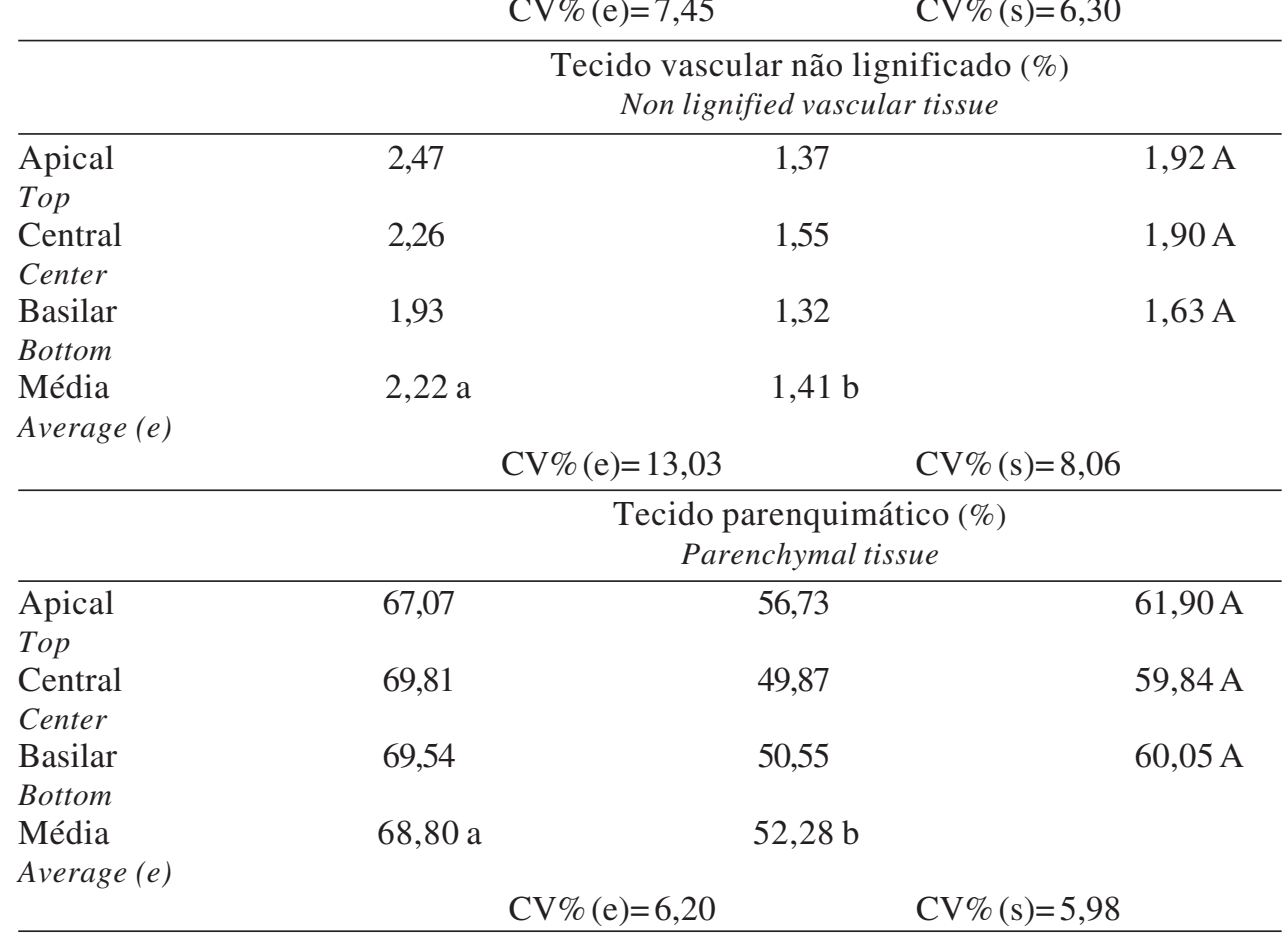


Continuação da Tabela $2 \ldots$

\begin{tabular}{|c|c|c|c|}
\hline & B. brizantha & B. humidicola & $\begin{array}{l}\text { Média } \\
\text { Average }\end{array}$ \\
\hline & \multicolumn{3}{|c|}{$\begin{array}{c}\text { Distância entre feixes vasculares } \\
\text { Distance among vascular bundles }(\mu \mathrm{m})\end{array}$} \\
\hline $\begin{array}{l}\text { Apical } \\
\text { Top }\end{array}$ & 338,95 & 190,38 & $264,67 \mathrm{~A}$ \\
\hline $\begin{array}{l}\text { Central } \\
\text { Center }\end{array}$ & 405,37 & 198,01 & $301,69 \mathrm{~A}$ \\
\hline Basilar & 345,47 & 232,14 & $288,81 \mathrm{~A}$ \\
\hline \multirow{3}{*}{$\begin{array}{l}\text { Média } \\
\text { Average (e) }\end{array}$} & $363,26 \mathrm{a}$ & $206,84 \mathrm{~b}$ & \\
\hline & \multicolumn{2}{|c|}{$\mathrm{CV} \%(\mathrm{e})=10,57$} & $\mathrm{CV} \%(\mathrm{~s})=19,42$ \\
\hline & \multicolumn{3}{|c|}{$\begin{array}{l}\text { Número total de feixes vasculares } \\
\text { Total number of vascular bundles }\end{array}$} \\
\hline $\begin{array}{l}\text { Apical } \\
\text { Top }\end{array}$ & 46,80 & 48,60 & $47,70 \mathrm{~A}$ \\
\hline $\begin{array}{l}\text { Central } \\
\text { Center }\end{array}$ & 41,80 & 44,00 & $42,90 \mathrm{AB}$ \\
\hline $\begin{array}{l}\text { Basilar } \\
\text { Bottom }\end{array}$ & 39,40 & 36,80 & $38,10 \mathrm{~B}$ \\
\hline \multirow{2}{*}{$\begin{array}{l}\text { Média } \\
\text { Average (e) }\end{array}$} & $42,67 \mathrm{a}$ & $43,13 \mathrm{a}$ & \\
\hline & \multicolumn{2}{|c|}{$\mathrm{CV} \%(\mathrm{e})=7,71$} & 90 \\
\hline
\end{tabular}

(s) - Região; (e) - espécies.

(s) - Region; (e) - species.

Letras iguais maiúsculas na coluna e minúsculas na linha não diferem significativamente $(P>0,05)$. Averages followed by the same capital letters in column and small letters in row do not differ $(P>05)$. 
Tabela 3 - Área (\%) dos tecidos e número de feixes vasculares no colmo de Brachiaria brizantha e $B$. humidicola, em três regiões da planta

Table 3 - Tissue area and number of vascular bundles in stem of Brachiaria brizantha and $B$. humidicola, at three plant regions

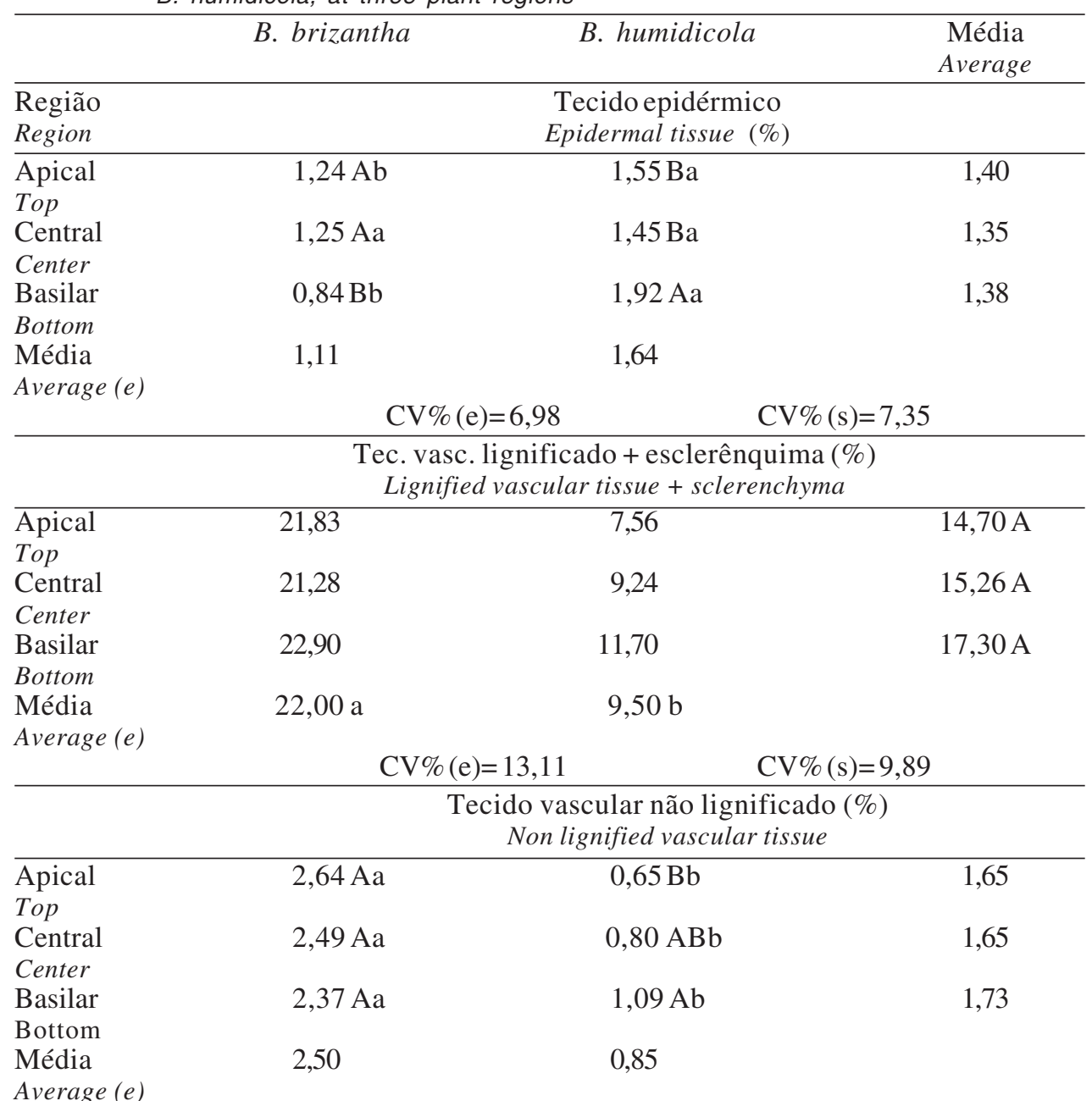

\begin{tabular}{|c|c|c|c|}
\hline & & & \\
\hline & & $\begin{array}{l}\text { arenquimáti } \\
\text { ymal tissue (? }\end{array}$ & \\
\hline Apical & 74,26 & 55,28 & $64,77 \mathrm{~A}$ \\
\hline Top & & & \\
\hline Central & 74,99 & 59,87 & $67,43 \mathrm{~A}$ \\
\hline Center & & & \\
\hline Basilar & 73,90 & 60,85 & $67,38 \mathrm{~A}$ \\
\hline Bottom & & & \\
\hline Média & $74,38 \mathrm{a}$ & $58,66 \mathrm{~b}$ & \\
\hline Thenge & & & \\
\hline & & $\begin{array}{l}\text { al de feixes } \\
\text { er of vascula }\end{array}$ & \\
\hline Apical & $89,40 \mathrm{Aa}$ & $38,80 \mathrm{Bb}$ & 64,10 \\
\hline Top & & & \\
\hline Central & $90,20 \mathrm{Aa}$ & $43,20 \mathrm{ABb}$ & 66,70 \\
\hline Center & & & \\
\hline Basilar & $83,40 \mathrm{Aa}$ & $46,80 \mathrm{Ab}$ & 65,10 \\
\hline Bottom & & & \\
\hline Média & $87,67 \mathrm{a}$ & $42,93 \mathrm{~b}$ & \\
\hline 11 & & & \\
\hline
\end{tabular}

(s) - Região; (e) - espécies.

(s) -Region; (e) - species.

Letras iguais maiúsculas na coluna e minúsculas na linha não diferem significativamente $(P>0,05)$.

Averages followed by the same capital letters in column and small letters in row do not differ $(P>.05)$. 


\section{Conclusões}

A B. brizantha apresentou maior área de tecido vascular lignificado nas três frações estudadas (limbo, bainha e colmo) em relação à $B$. humidicola. A área de tecido parenquimático foi maior na bainha e no colmo para as duas espécies.

A B. brizantha apresentou maior distância entre os feixes vasculares no limbo e na bainha, enquanto o número foi maior no limbo e no colmo.

A área de tecido vascular lignificado foi menor no limbo da região basilar em relação à apical. O número de feixes vasculares foi maior no limbo da $B$. brizantha e na média das duas espécies, na bainha foliar.

\section{Agradecimento}

À EPAGRI S.A. - E.E.Itajaí, pelo fornecimento do material vegetal, pelas instalações e pela manutenção do experimento.

\section{Literatura Citada}

ALVES DE BRITO, C.J.F. Organização estrutural e degradação in vitro de tecidos em Pennisetum purpureum Schum. (Poaceae). Curitiba: Universidade Federal do Paraná, 1997. 119p. Dissertação (Mestrado em Botânica) - Universidade Federal do Paraná, 1997.

ALVES DE BRITO, C.J.F., ALQUINI, Y. A new method for staining botanical material embedded in glycol methacrylate. Arquivos de Biologia e Tecnologia, v.39, n.1, p.949-951, 1996.

ALVES DE BRITO, C.J.F.; ALQUINI, Y.; RODELLA, R.A. et al. Perfil anatômico dos tecidos de três ecotipos de capimelefante (Pennisetum purpureum Schum.). In: REUNIÃO ANUAL DA SOCIEDADE BRASILEIRA DE ZOOTECNIA, 34., 1997, Juiz de Fora. Anais... Juiz de Fora, Sociedade Brasileira de Zootecnia, 1997a, v.2, p.9-11.

ALVES DE BRITO, C.J.F.; ALQUINI, Y.; RODELLA, R.A. et al. Alterações histológicas de três ecotipos de capim-elefante (Pennisetum purpureum Schum.), após digestão in vitro. In: REUNIÃO ANUAL DA SOCIEDADE BRASILEIRA DE ZOOTECNIA, 34., 1997, Juiz de Fora. Anais... Juiz de Fora: Sociedade Brasileira de Zootecnia, 1997b. v.2, p.12-14.

ALVES DE BRITO, C.J.F.; DESCHAMPS, F.C. Caracterização anatômica de Hemarthria altissima (Poir) Stapf \& C.E. Hubb (Poaceae). In: REUNIÃO ANUAL DA SOCIEDADE BRASILEIRA DEZOOTECNIA, 35., 1998, Botucatu. Anais... Botucatu: Sociedade Brasileira de Zootecnia, 1998. p.675-677.

ALVES DE BRITO, C.J.F.; RODELLA, R.A.; DESCHAMPS, F.C. et al. Anatomia quantitativa e degradação in vitro de tecidos em cultivares de capim-elefante (Pennisetum purpureum Schumach.). Revista Brasileira de Zootecnia, v.28, n.2, p.223-229, 1999.

DESCHAMPS, F.C. Implicações do período de crescimento na composição química e digestão dos tecidos de cultivares de capim-elefante. Revista Brasileira de Zootecnia, v.28, n.6, p.1358-1369, 1999.

DESCHAMPS, F.C.; ALVES DE BRITO, C.J.F. Qualidade e participação das diversas frações de três cultivares de capim elefante (Pennisetum purpureum Schumach.). In: REUNIÃO ANUAL DA SOCIEDADE BRASILEIRA DE ZOOTECNIA, 35., 1998, Botucatu. Anais... Botucatu: Sociedade Brasileira de Zootecnia, 1998. p.548-550.

FEDER, N.; O'BRIEN, T.P. Plant microtechnique: some principles and new methods. American Journal of Botany, v.55, n.1, p.123-142, 1968.

HATFIELD, R.D.; RALPH, J.; GRABBER, J.H. Cell wall crosslinking by ferulates and diferulates in grasses. Journal of Science Food Agriculture, v.79, p.403-407, 1999a.

HATFIELD, R.D.; RALPH, J.; GRABBER, J.H. Cell wall structural foundations: molecular basis for improving forage digestibility. Crop Science, v.39, p.27-37, 1999 b.

JOHANSEN, D.A. Plant microtechnique. New York: Mc Graw Hill Book, 1940. 523p.

JUNG, H.G.; ALLEN, M.S. Characteristics of plant cell walls affecting intake and digestibility of forages by ruminants. Journal of Animal Science, v.73, p.2774-2790, 1995.

JUNG, H.G., BUXTON, D.R. Forage quality variation among maize inbreeds: relationships of cell-wall composition and in-vitro degradability for stem internodes. Journal of Science Food Agriculture, v.66, p.313-322, 1994.

JUNG, H.G.; NI, W. Lignification of plant cell walls: impact of genetic manipulation. Proceedings of the National Academy of Science, v.95, p.12742-12743, 1998.

LIMA, L.M.S. Caracterização anatômica, anatomia quantitativa e análise da degradação ruminal de colmos e folhas de cultivares de Axonopus scoparius (Flügge) Kuhlm. e Axonopus fissifolius (Raddi) Kuhlm. (Poaceae). Curitiba: niversidade Federal do Paraná, 1998. 87p. Dissertação (Mestrado em Botânica) - Universidade Federal do Paraná, 1998.

PACCIULO, D.S.C.; MATTOS, J.L.S.; GOMIDE, J.A. et al. Proporção de tecidos e espessura da parede celular em espécies de braquiária, cultivadas sob diferentes níveis de umidade no solo. In: REUNIÃO ANUAL DA SOCIEDADE BRASILEIRA DE ZOOTECNIA, 36., 1999, Porto Alegre. Anais... Porto Alegre: Sociedade Brasileira de Zootecnia, 1999. p.37.

PIMENTEL-GOMES, F. Curso de estatística experimental. 6 ed. Piracicaba: Binetti, 1976. 430p.

RODELLA, R.A.; ISHIY, C.M.; MAIMONI-RODELLA, R.C.S. et al. Estudo quantitativo de características anatômicas de folhas de duas espécies de Brachiaria. Revista Agrociência, v.2, n.2, p.21-30, 1982.

VENTRELLA, M.C. Anatomia quantitativa e composição bromatológica de folha e colmo de três espécies de Cynodon Rich. Botucatu: Universidade Estadual Paulista, 1995. 127p. Dissertação (Mestrado em Botânica) - Universidade Estadual Paulista, 1995.

VENTRELLA, M.C.; RODELLA, R.A.; COSTA, C. et al. Anatomia e bromatologia de espécies forrageiras de Cynodon Rich. I. Folha. In: REUNIÃO ANUAL DA SOCIEDADE BRASILEIRA DE ZOOTECNIA, 34., 1997, Juiz de Fora. Anais... Juiz de Fora: Sociedade Brasileira de Zootecnia, 1997a. v.2, p.3-5.

VENTRELlA, M.C.; RODELlA, R.A.; COSTA, C. et al. Anatomia e bromatologia de espécies forrageiras de Cynodon Rich. II. Colmo. In: REUNIÃO ANUAL DA SOCIEDADE BRASILEIRA DE ZOOTECNIA, 34., 1997, Juiz de Fora. Anais... Juiz de Fora: Sociedade Brasileira de Zootecnia. 1997b, v.2, p.6-8.

WILSON, J.R. Variation of leaf characteristics with level of insertion on a grass tiller. II. Anatomy. Australian Journal of Agricultural Research, v.27, p.355-364, 1976.

Recebido em: 28/10/02 Aceito em: 25/06/03

R. Bras. Zootec., v.33, n.3, p.519-528, 2004 